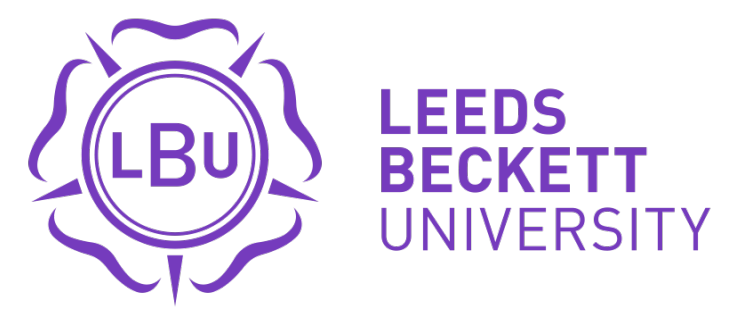

Citation:

Holbrey, CE (2020) Kahoot! Using a game-based approach to blended learning to support effective learning environments and student engagement in traditional lecture theatres. Technology, Pedagogy and Education. ISSN 1475-939X DOI: https://doi.org/10.1080/1475939X.2020.1737568

Link to Leeds Beckett Repository record:

https://eprints.leedsbeckett.ac.uk/id/eprint/5889/

Document Version:

Article (Accepted Version)

This is an Accepted Manuscript of an article published by Taylor \& Francis in Technology, Pedagogy and Education on 12 March 2020, available online: http://www.tandfonline.com/10.1080/1475939X.2020.1737568

The aim of the Leeds Beckett Repository is to provide open access to our research, as required by funder policies and permitted by publishers and copyright law.

The Leeds Beckett repository holds a wide range of publications, each of which has been checked for copyright and the relevant embargo period has been applied by the Research Services team.

We operate on a standard take-down policy. If you are the author or publisher of an output and you would like it removed from the repository, please contact us and we will investigate on a case-by-case basis.

Each thesis in the repository has been cleared where necessary by the author for third party copyright. If you would like a thesis to be removed from the repository or believe there is an issue with copyright, please contact us on openaccess@leedsbeckett.ac.uk and we will investigate on a case-by-case basis. 


\section{Kahoot! Using a game-based approach to blended learning to support effective learning environments and student engagement in traditional lecture theatres}

\section{Christine Elizabeth Holbrey}

Carnegie School of Education, Leeds Beckett University

Carnegie School of Education, Leeds Beckett University, Carnegie Hall Room 124, Headingley Campus, Leeds, LS6 3QQ, UK

Telephone: 01138127413 Email: c.e.holbrey@leedsbeckett.ac.uk

The author is a senior lecturer in education and initial teacher training at Carnegie School of Education, Leeds Beckett University. Her passions, both as a practitioner and researcher, have focused on the continuum of professional development and supporting the development of teams of outstanding people who can deliver outstanding, relevant and engaging learning. She works within both undergraduate and postgraduate teams delivering face to face and online learning. Recent research has focused on the impact of social media in initial teacher training and the development of online learning communities. Prior to her current role the author had an extensive career as a secondary school teacher, senior leader, education consultant and headteacher. 


\title{
Kahoot! Using a game-based approach to blended learning to support effective learning environments and student engagement in traditional lecture theatres
}

\author{
Traditional lecture theatre environments present significant challenges in higher \\ education, in light of increasingly large and diverse student populations. This \\ small scale study explores how blended learning through the game-based \\ platform Kahoot! can be used to enhance the learning experience offered to \\ students in these spaces, from the perspective of 44 final year primary education \\ undergraduates. An action research approach was employed with data collected \\ from pre- and post-lecture surveys. Findings suggest that the integration of \\ synchronous online learning in lecture theatres presented no technical difficulties \\ and that gaming was successful in enabling active participation and interactive \\ learning. Students valued its competitive nature, the immediacy of feedback on \\ their knowledge and structured opportunities for further discussion. Students \\ reported improvements in engagement, concentration and retention although \\ results for the latter were more ambiguous and would benefit from further \\ investigation.
}

Keywords: Kahoot!; lecture theatre; student engagement; blended learning; learning environment

\section{Introduction}

There has been much research on the confinements of traditional lecture theatres and the limitations they place on teaching, depth of learning and assessment opportunities as well as the challenges faced by increasingly large, and more diverse, student populations (Arvanitakis, 2014; Biggs \& Tang, 2011; Bligh, 2000; Petrovic \& Pale, 2015). Interestingly, more recent research (Bates et al., 2017; French \& Kennedy, 2017; Sharp et al., 2017) approaches the subject from a realisation that lectures will remain as the dominant mode of delivery in higher education but recognise that pedagogical practices need to be modified, and improved, to cater for the changing nature of student cohorts. 
Sharp et al. (2017), having researched academic boredom, suggest it is not unreasonable to expect universities to think very carefully about improving course design and delivery, with students placed at the heart of transformational thinking, and serious consideration given to the implications of teaching, learning and assessment on the student experience, their emotional attachment and overall satisfaction. As student voice becomes an increasingly important driver in institutional rankings it would seem prudent for academic staff to consider how alternative approaches, such as blended learning, can be integrated into their teaching to support more active participation and better engagement which in turn improves the learning experience for students and the quality of their outcomes (Cavanagh, 2011; Okaz, 2015; Wolff et al., 2015).

This paper emerged as a result of a growing pedagogical discontent in lecture theatres, which Tormey \& Henchy (2008) recognise is more acute in teacher educators because their content is often linked to the philosophy of education. It explores the issues raised and students' reactions to the introduction of a game-based approach to blended learning in the lecture theatre through the online platform Kahoot! While acknowledging the small scale nature of the study, students' perceptions of their engagement, information retention and concentration are examined in a hope to inspire colleagues to harness the advantages of technology, creatively and innovatively, to enhance the learning environment in traditional lecture spaces.

\section{Literature review}

Since the 1960s class sizes in higher education institutions have continued to increase and we are faced with what Arvanitakis (2014) refers to as the 'massification' of higher education systems, a term used to describe the rapid increase in student enrolment. Driven by anticipated gains in social and economic prosperity, as well as financial 
pressures to accept increasing student numbers, this widening participation agenda has produced a much more diverse composition of students and a move away from the notion of universities as centres of elite education for the few (Hornsby \& Osman, 2014). For many academics, large group teaching is a reality with traditional lecture theatres being used to accommodate the increased student populations, providing a cost effective means of course delivery. Despite some inherent disadvantages, lecturing still remains one of the most common methods of teaching in higher education (Biggs \& Tang, 2011; Goffe \& Kauper, 2014; Petrovic \& Pale, 2015; Schmidt et al., 2015).

Bligh (2000, p. xiii) defines lecturing as 'more or less uninterrupted talk from a teacher' and argues where the primary function of the lecture is information transmission, lectures are as effective as anything else. Students benefit from face-toface delivery and lecturers have the ability to deliver content simultaneously to everyone. A study of overspill rooms (Exeter et al., 2010), catering for cohorts over 550 , found that students valued the live narrative, and that the face-to-face presence of the lecturer was a key feature in motivating students and keeping them on track. One participant even suggested that the course was naturally interesting simply because of the content taught, which lends weight to the defence of lectures as 'critical opportunities to expose student to, and guide them through, current academic developments in the field' (Biggs \& Tang, 2011, p. 138).

This empirical picture of practice has been the target of considerable educational debate. Didactic lecturing has been criticised for its 'one size fits all' approach which Arvanitakis (2014) argues, demonstrates little or no understanding of the sophisticated ways in which students learn. Schmidt et al. (2015) and Wolff et al. (2015) add to this debate raising concerns about the tendency of lecture spaces to encourage 'instructivist' approaches, where the student is a passive recipient of knowledge, and the fallacy of 
information transmission which they suggest ignores constructivism and situated cognition. Schmidt et al. (2015) strongly believe that the student has to 'do' something with information for it to make sense to them, to remember it and to be able to use it in the future.

A survey by Goffe \& Kauper (2014) found that the norms of professional practice were heavily influenced by individual subject disciplines and the lecturer's own perceptions of what constitutes a 'good' educational experience. While they found most lecturers to be student-focused, much practice was in direct contradiction to their own beliefs on how best to teach, with content coverage, time, student resistance, room layout and even degree readiness being cited as reasons for adopting more didactic styles. Whilst acknowledging the pedagogical benefits of listening and note taking, notably of information synthesis, there is general agreement that lecturers need to do more to promote active learning and critical thinking for a deeper understanding of content and retention of knowledge (Exeter et al., 2010; French \& Kennedy, 2017; Tormey \& Henchy, 2008).

When done well, it seems that lectures, and lecturers, can focus attention, be informative, engaging, inspiring and even provide a transformational learning experience (French \& Kennedy, 2017; Petrovic \& Pale, 2015). Biggs \& Tang (2011) point out that a skilled practitioner can supports students' construction of knowledge and check understanding through eye contact and observation, although they do recognise that this becomes more difficult with larger groups. French and Kennedy (2017) suggest that recent debates over student concentration spans, or lack of them, may be more to do with the ability of the lecturer to engage than any pre-disposition on behalf of the student. It should also be remembered that lectures are rarely the sole means of course delivery and criticisms should be levied mindful of their intended 
purpose, which may include, as Arvanitakis (2014) intimates, a social function. Bates et al. (2017) add strength to this claim, suggesting that lectures help students feel part of the learning community and gives them a sense of belonging, which in turn, supports learning. The picture presented is then that student attitudes to, and attendance towards, lectures may be affected by a complex range of issues. Research by Petrovic \& Pale (2015) while acknowledging that boredom and dissatisfaction may have some bearing on absence, found that family commitments, illness, the need to undertake paid employment and travel issues were more prevalent.

Despite the advantages of lecture spaces, research literature is heavily weighted towards the disadvantages, and the challenges for staff teaching in them, particularly in terms of developing effective and engaging learning environments (Biggs \& Tang, 2011; Bligh, 2000; Hornsby \& Osman, 2014; Saunders \& Gale, 2012). Researchers are in agreement that anonymity, of student to lecturer, is a problem, with large classes preventing the establishment of interpersonal relationships necessary to respond to the needs of individual students. A study by Petrovic \& Pale (2015) found that students are less likely to ask questions in a large group to test their knowledge and understanding of content, and little feedback, if any, is given by the lecturer. They suggest that students actually resist interactions because they feel threatened and uncomfortable. Okaz (2015) extends this thinking, and calls for a more collaborative learning experience congruent with successfully achieving high order learning outcomes. Bligh (2000), while advocating lectures for information transmission, agrees that where thought and deep learning are required, discussion is better and condemns archaic fixed rows of seating which actively discourage intellectual conversation.

Wells \& Daunt (2016) pick up on the theme of emotional and practical discomfort in their Eduscape paper pointing out that comfort, or discomfort, in the 
lecture theatre is directly linked to levels of concentration arguing that low seating, lack of leg space and thin desks are problematic. Modern central heating is also assumed to induce drowsiness (Bligh, 2000); however, Wells \& Daunt (2016) found that while optimum temperatures may be subjective, students generally found lecture theatres of a comfortable temperature and humidity. Higher levels of off-task noise was also raised as another issue; however, it may simply be that in an era of widening participation, many students are not ready for independent learning and display symptomatic behaviours including in-class chatter, poor attendance and disruptive use of mobile devices. Similar 'coping strategies' were identified by Sharp et al. (2017) when students were not actively engaged, or where little mental processing was required, and raise the question as to whether academic boredom is 'imported' or 'acquired' whilst at university.

Despite a number of pedagogical failings, it seems lectures are here to stay but, it has been argued, they must be reimagined and improved by incorporating active, interactive and discursive teaching strategies (Cavanagh, 2011; French \& Kennedy, 2017; Saunders \& Gale, 2012; Schmidt et al., 2015; Wolff et al, 2015). These sentiments are echoed by Arvanitakis (2014, p. 740), a strong advocate of perfecting the lecture rather than supplanting it; he argues that 'massification should be seen as an opportunity to ensure higher education is available to an increasing proportion of the population who were historically denied access to university'. The success of such strategies is, however, dependent on avoiding the 'vigilance decrement', the simple breaking up of the lecture to avoid loss of concentration, and must be part of a wellstructured and well-designed experience to facilitate deep learning.

As 21st century educators, we should embrace technological innovations to confront the challenges of large cohort teaching. Blended learning is a design approach 
which integrates the strengths of face to face learning and online learning to address worthwhile educational goals and transform the learning experience (Glazer, 2012; Masikunis et al., 2009; Okaz, 2015; Saunders \&Gale, 2012). What makes blended learning particularly effective is its ability to facilitate a community of learners and provide conditions which encourage dialogue and debate, the hallmarks of higher education. The work of Luckin (2010) on redesigning learning environments through technologically rich learner-centred ecologies is inspirational, as she investigates the link between physical 'context' and the notions of social environment. While Petrovic \& Pale (2015) identify the importance of lectures as social spaces, Luckin (2010) draws on Vygotsky's zone of proximal development as the most suitable theoretical basis to support her ideas of productive and collaborative learning contexts and the role of technology in scaffolding learning.

The inclusion of a social dimension of learning within a networked society builds on new connectivist pedagogies and attempts to overcome criticism of early full online courses by minimising social isolation and developing communities of engaged interactive learners (Okaz, 2015). While there are many supporters of blended learning, others display humanistic opposition and are reluctant to engage. Interestingly, while a networked society draws mistrust and suspicion from some, there are other sceptics who retain an instructionist view of technology, endorsed by its visual nature, which depicts a more passive learning experience. On a more practical basis however, teachers may simply vary in their digital confidence and competence and need to be supported, and encouraged, through high quality professional development.

Whereas professional development is a 'must' for some academics, Grimley et al. (2011) point out that the majority of students have been raised in a technological era and it is reasonable to assume that they will thrive in a similar environment. They make 
the distinction however that the 'net generation' and are only engaged if learning by interaction, through experience and in exploratory ways, concurring with the ideas of Luckin (2010) on learning through social collaboration. Saunders \& Gale (2012) while supporting this view, point out that it has been recently criticised and a view of students as less prolific users of technology is beginning to emerge. Snart (2010), an avid advocate of technology, provides a useful example in his work illustrating the student who maintains a vibrant interactive Facebook page but who does not approach online discussion boards with the same vigour or enthusiasm. He implies that technologies only offer a quick and convenient way to interface which may not align with traditional higher education pedagogical goals of considered reflection, deep learning and sophisticated formal language.

This study seeks to explore the links between technologies favoured by students and learning considered important in higher education, through the adoption of a gamebased approach to blended learning. There has been much research on the motivational function of gaming and its ability to support improved engagement and participation through competitive incentives commonly including points, leader boards and trophies. Zarzycka-Piskorz (2016) believe that fun is the key element in the success of gaming in that it breaks routine and boredom, while Aljezawi \& Albashtawy (2015) focus on improvements in mood, creativity and morale and allude to an experience described by Csikszentmihalyi as 'flow', the highly motivational and pleasant state experienced by learners engrossed in an activity.

The use of play in education is not a new phenomenon; however, when applied to technological gaming Wang \& Lieberoth (2016) suggest that educational gaming is not as advanced as mainstream gaming. While mastering cognitive thinking, through immediate feedback, is a key element of gaming strategy (Plass et al., 2015; Tormey \& 
Henchy, 2008) a number of studies have lent weight to the notion that while gamebased learning is fun, exciting and motivational as a leisure pursuit, there is much less satisfaction within the educational environment and academic outcomes are not always realised (Grimley et al., 2011; Plump \& LaRosa, 2017; Saunders \& Gale, 2012). To some academics, gaming offers little scholarly merit; nevertheless, the value of gamebased learning as a vehicle for teaching concepts while inspiring students is widely accepted.

The online gaming tool chosen for this study was Kahoot!; a global learning platform reminiscent of former student response systems or 'clicker' technology. Once registered, instructors create instructors create quizzes, discussions or surveys, or adapt publically available ones. It requires no sophisticated equipment, the basic Kahoot! package is available free of charge as long as it is used for non-commercial purposes, with paywall service plans available for more advanced usage. Students do not need to register; they just sign in on the web address to access the platform (Marello, 2014). The interface is easy to use, accessible from any web enabled device and utilises the free Wi-Fi networks found in higher education, negating some of the cost constraints raised as reasons for lecturers' aversion to didactic alternatives (Goffe \& Kauper, 2014).

Kahoot! offers the opportunity for an improved pedagogical experience and escape from the habitus of didactic lecturing in large theatres, with its traditional teacher centred approaches and lack of social interaction. It forces participation, supporting improved engagement and enables formative assessment of prior knowledge in a fun, contemporary and innovative manner. Feedback informs the lecturer which concepts students are having difficulty with and through further discussion helps reinforce learning and access to deeper levels of thinking, in turn supporting personalised learning and inclusion. 


\section{Research in action}

The aim of this research is to contribute to a better understanding of the benefits of using an online gaming platform in large lecture theatres with regard to the impact on the learning environment and the student learning experience. More specifically the research objective is to understand how students experienced Kahoot! and to explore the extent of which participation with synchronous technology influenced their engagement, retention and concentration. A mixed methods action research approach was employed to address the research objectives with the impetus for innovation arising from a growing pedagogical discontent of didactic lecture approaches.

Action research is about evaluating your practice to check whether it is as good as you would like it to be, identifying areas that you feel need improving, and finding ways to improve them (McNiff, 2016 p.9)

Quantitative data was sort through a Likert scale measure alongside more open, qualitative, responses which would be more indicative of the intricacies involved in human perceptions, especially those related to engagement and motivation. Analysis focused on both data sources with the intention of revealing complex perceptions and issues relating to the use of Kahoot! in the context of student engagement, retention and concentration. This approach enhances the insights gained from the literature review and provides more specific interpretations in relation to trainee teacher perceptions of using game-based approaches to blended learning in supporting effective learning environments and student engagement in traditional lecture theatres.

The learning platform Kahoot! was used to support the delivery of a two hour lecture, to final year undergraduate trainee teachers $(n=44)$, on part 2 of the Teacher Standards. The captive nature of the audience could be considered a limitation of the study, especially considering the ethical issues of power differentials and coercion 
raised by many authors (Cohen et al., 2011; McNiff, 2016). However, self-reflection permeates through the primary education course and is a central part of students' professional development while on school placement thus engendering confidence in the quality, and honesty, of student feedback. This view is supported by Cavanagh (2011) who argues that the pre-disposition of trainee teachers to be naturally interested in pedagogy enables them to be more critical from the perspective of both the teacher and the learner.

Students were introduced to 11 multiple choice questions throughout the lecture, designed to test prior knowledge of the subject content matter in a fun, non-threatening manner. During the Kahoot! gameplay, the brightly coloured quiz was projected onto the main screen and students responded synchronously, in real time, by pressing the corresponding answer on their individual devices, to accrue points and top the graphically displayed leader board. An advantage of Kahoot! is that students can join anonymously, reducing possible issues of embarrassment and humiliation often associated with competitive gaming (Heaslip et al., 2014; Plump \& LaRosa, 2017). Technical difficulties were minimised through students' previous exposure to Kahoot! and responses were used to drive further discussions, address misconceptions, consolidate knowledge and extend thinking providing as part of a layered feedback approach. At the end of the session the newly acquired knowledge was applied to a number of real life scenarios, which Marello (2014) calls the 'learner to leader loop', a central aspect of successful gaming pedagogy.

As part of the lecture, students were asked to complete a pre and post-event survey with ethical approval sought and granted in accordance with university protocols. Student participation was voluntary, through anonymous self-selection and informed consent, within the context of a 'captive' audience. The response rate of 
convenience sampling, recognised by Cohen et al. (2011), was high at 100\% $(\mathrm{n}=44)$. However, this accounted for just under half of the total cohort $(n=96)$ and presents a limitation in that the sample may not be representative of the full cohort and is relatively small.

The pre-event survey consisted of 3 key closed questions on engagement, retention and concentration with responses on a five point Likert scale: 'never' to 'all of the time', with each question having additional space for further qualitative responses. Questions were derived from existing research literature, and the educational experience of the author, and were presented to academic colleagues for feedback, ensuring a degree of content and face validity. An odd scale was chosen to allow for neutral responses and brevity was used to aid the response rate and detail in the qualitative responses. The same 5 point scale was used in the post-event survey with some slight amendments to the wording, from 'not at all' to 'very useful'. It could be argued that this prevents direct comparison; however, the intention was to get students to really think about the impact of a blended approach on their learning and avoid a simple, and expected, positive increase in responses. Two additional questions relating to the perceived usefulness of facilitated discussion time during the lecture and the value of interactive delivery were also asked, again with space available for further qualitative responses.

\section{Presentation of findings}

The pre-event survey results suggest that traditional lecture theatre spaces do not provide particularly engaging environments (Table 1).

[Insert Table 1 as close to here as possible]

Only 15 respondents $(34.1 \%)$ felt they were engaged most of the time with a worrying 
$29(65.9 \%)$ believing that that they were engaged half of the time or less. Interestingly, no students responded at the extreme end of the five-point scale 'never' and 'all of the time' with regard engagement with a similar picture evident for retention of information and concentration. Sharpe et al. (2017) urge caution with immediate instincts to demonise the lecture and advise a clear focus on student feedback which, as in their study, provided clear ingredients for effective engagement with qualitative responses overwhelming centring on relevancy of content (34.1\%), quality of speakers $(22.7 \%)$ and the length of lectures $(22.7 \%)$.

These finding appear to support claims that a lively exposition by an enthusiastic and charismatic individual is crucial to successful didactic teaching (Biggs \& Tang, 2011; French \& Kennedy, 2017). Content relevancy and speaker quality also factored highly in relation to 'retention' of information and student's perceived ability to 'concentrate'. While $10(22.7 \%)$ thought the length of lectures affected their engagement, another $3(6.8 \%)$ also felt it affected their concentration and 24 individual students made qualitative comments suggesting more short and focused lectures would be an improvement. One student wrote:

I don't think the issue is style and content, I think it's the length of time some lectures last. Siting in a stuffy lecture theatre for 2 hours or more can massively affect engagement and concentration (Student A).

Other students alluded to cramped and uncomfortable seating arrangements in traditional lecture theatres which is congruent with the observations of Wells \& Daunt (2016), who note that various constructs of the physical design are instrumental in students' perceived pleasure, or displeasure, in their environment.

Low level disruption from fellow students was cited by two individuals (4.6\%) as impacting on their engagement, with both respondents calling for this behaviour to be 
better managed by lecturers. This is consistent with Moore \& Gilmartin (2010, p. 334) who reflected on the role of lecturers being at the 'intersection of entertainment and crowd control'. Unproductive noise was also clearly evident in concentration feedback, with 9 (20.4\%) noting being easily distracted by other students chatting:

It's hard to concentrate when people talk in rows in front and behind (Student B).

Unexpectedly, 9 (20.5\%) commented on the need for additional lecture support materials to be made available on the University's VLE with a further 8 (18.2\%) making reference to the importance of note-taking in relation to supporting information retention, indicating perhaps again the value of content relevancy, yet failing to make the connection, as only $1(2.3 \%)$ student did, between the lack of questioning opportunities in traditional style lectures and the impact on information retention. Two students did however express the need for recap sessions in seminars to reinforce learning and another $2(4.6 \%)$ reflected on didactic approaches not being conducive to their learning and affecting concentration, clearly indicated a preference for seminars and valuing the greater opportunities for discussion and debate.

This view was echoed by 13 individuals who recommended increasing interaction in lectures as a means of improvement and concurs with Sharp et al. (2017) who found that students preferred seminar sessions, citing more interactive and closer personalised relationships as reasons for their preference. In direct contrast to these findings, another student compared her experience of lectures to seminar sessions implying more negative perceptions of the latter and defending transmission modes of delivery:

I like the way information is delivered in lectures, it gives the opportunity for each of us to take what we deem important from it. This is in comparison to seminars 
when sometimes participation is forced in activities that do not feel directly related to my professional development (Student C).

It appears that students are self-aware, and strategic, in their approaches to learning. French \& Kennedy (2017) consider the supposed dichotomy between lectures and seminars as unhelpful, suggesting that both require skill in design and delivery to facilitate learning. However, it is clear from an over-reliance by some on note taking that not all students are fully engaged in the process of critical thinking and 'sense making' during lectures, one of the core graduate attributes.

The post-event survey results show that 35 (79.5\%) respondents felt Kahoot! had been useful or very useful in improving their engagement and $33(75.0 \%)$ felt it was useful or very useful in supporting better concentration throughout the lecture. However, a sizeable minority, 20 (45.5\%) felt it was only 'fairly useful' or 'not very useful' in helping them retain information (Table 2). Again, no students respond at the extreme of 'not at all useful' but there was a shift in the range of scale utilised at the opposite end to include 'very useful' indicating raised perceptions in all areas.

[Insert Table 2 as close to here as possible]

Students were overwhelmingly positive about the value of developing more interactive learning environments within traditional lecture spaces; 40 (90.9\%) of respondents strongly acknowledged their usefulness, and 11 (25\%) individual students made specific remarks about Kahoot! providing a more stimulating, fun and engaging atmosphere where they felt compelled to participate. One student wrote:

Provides information in an engaging way, better than just powerpoint! (Student D).

Recognition of the motivational aspects of gaming though increased interaction and participation are consistent with the work of Aljezawi \& Albashtawy (2015) who argue 
that it relieves the monotony of traditional lectures and Grimley et al. (2011) who introduce us to the 'arousal theory', akin to Csikszentmihalyi's flow, and suggest that bright lights and music improve the learning environment and support positive cognitive performance. Interestingly, another students recognising the element of 'forced compliance' remarked:

Liked that it was used alongside the lecture rather than as an add-on at the start or end. It's always fun and adds extra. It puts me in a happy place and makes me want to join in (Student E).

High spirits, laughter and noise observed by Wang \& Lieberoth (2016) were evident in the lecture theatre and there was clear evidence of a shift from the 'gimmick factor' of technology, which Masikunis et al. (2009) coined as 'early acceptance' and surface learning, towards 'divergence' and deep learning. In each of the key question areas, respondents made inferences to the facilitation of deep learning with terminology such as 'new learning', 'depth of learning', 'deep thinking' and 'application of thinking' being used. One student remarked:

You're re-thinking, whereas with just lecture talk the information is just said and then nothing else makes you use the information (Student F).

Clearly students valued the opportunity for meta-cognition during the lectures. Another student relishing how a blended approach helped improved the lecture design commented on how the session built on prior knowledge and scaffolded learning in a more supportive manner:

It's helpful to go into depth about some of the issues presented to make sure we have a secure understanding and can more easily apply the new knowledge to a range of real world scenarios (Student G). 
Petrovic \& Pale (2015) found students were well aware that prior knowledge influenced their understanding of lecture content and that 'testing' was useful to them. This is supported by $33(75 \%)$ who reflected positively on the usefulness of planned opportunities for discussion being integrated into the lecture, and 5 (11.4\%) commenting on the importance of knowing and understanding the 'extra' information behind the answers. A number however disagreed; 3 (6.8\%) felt the discussions were too long and $2(4.6 \%)$ talked about information overload. Interestingly, the length of discussion was guided by student contributions rather than by the lecturer solely determining the pace. Tormey \& Henchy (2008) point out that some students have difficulty regulating their own learning and need the lecturer to do this for them and their concentration spans have been the subject of much debate (Exley, 2010; French \& Kennedy, 2017). Future consideration should be given to both lecture design and length.

Two students raised connectivity and intermittent Wi-Fi signal as a problem but these appeared to be isolated comments and there were no other indications that the use of technology caused any technical issues. Students' previous introduction to Kahoot! factored favourably, with a number of individual comments around social collaboration and 'light-hearted' competitiveness as being strengths of Kahoot! While some academics might argue against these behavioural attributes, research into game-based learning, as in this study, continues to depict this as a key strength (Heaslip et al., 2014; Plass et al., 2015; Wang \& Lieberoth, 2016).

As in the pre-event survey, the lack of opportunity for note taking, and of hard copies was prevalent amongst a small, yet sizeable minority, of students and whilst this supports the outcomes of studies (Moore \& Gilmartin, 2010; Tormey \& Henchy, 2008), it does indicate a desire to return to more traditional modes of delivery as a result of the 
perceived impact on the important of content knowledge and retention of information. This direct conflict with research implying that increased interactions supports increased interest in subject matter which in turn consolidates short term memory and longer term retrieval (Aljezawi \& Albashtawy, 2015; Cavanagh, 2011; Exley, 2011) make it worthy of further investigation at a later date.

One insightful student, recognising perhaps the restrictions imposed by lecture theatres yet mindful of the need for more interactive and engaging spaces, wrote:

Very useful and carefully considered. From my own experience we don't like getting up and moving about lots in lectures (Student $\mathrm{H}$ ).

This raises the possibilities of potential challenge from students when trying to change the 'norm' which Heaslip et al. (2014) recognised in their study on electronic response systems. They found that some students prefer to be 'passive' learners and even resist learner centred approaches as they take a little more effort on the part of the student and may require more unsupported and independent work. Despite this slight ambiguity authenticity remained a strong theme throughout student responses, as in the pre-survey, with content and activity relevance to professional practice cited as impacting on engagement, concentration and to a slightly lesser extent retention.

\section{Discussion and conclusions}

In an era of widening participation (Arvanitakis, 2014; Hornsby \& Osman, 2014) recognise the difficult journey for many students, especially those from non-traditional backgrounds and the challenges that massification presents for the academic staff teaching large groups. They argue it is critical for universities to provide environments which encourage active learning and support the emotional development of being and becoming a higher education student. 
Whilst the academic and perhaps pedagogical debates around the value of lectures continues, they will no doubt continue to exist in higher education because of tradition, their convenience for large class teaching and the recognition of the importance of face to face contact (French \& Kennedy, 2017; Goffe \& Kauper, 2014). This limited small scale study does however tentatively imply that the humble lecture does need to be 'reimagined' in order to facilitate more active engagement, to improve the learning environment for students and to support the graduate attributes of selfempowered critical thinkers.

By embracing a game-based approach to blended learning the traditional lecture theatre environment was transformed into an interactive space for dialogue and discussion, overcoming the highly criticised passivity dominant in much didactic transmission (Aljezawi \& Albashtawy, 2015). Students valued the approach and found it created a more effective learning environment, improved understanding and helped maintain interest during the two hour session.

Students were particularly complementary about active participation and the fun elements of competitive gaming which is concurrent with existing academic literature on the motivational aspects of gaming (Plass et al., 2015; Wang \& Lieberoth, 2016; Zarzycka-Piskorz, 2016). There were simple yet significant changes in both the atmosphere and level of verbal discourse with similar findings to Wang \& Lieberoth (2016) of high spirits, laughter, productive noise, and a highly responsive class.

Students were also decisive in their views around the value of facilitated discussion and opportunities to extend thinking through collaboration, and while this may conflict directly with some of the competitive elements of gaming, it plays a major part in connectivist thinking and supports Luckin's (2010) ideas that the 'net' generation are only engaged if learning by interaction, through experience and in 
exploratory ways. There was a clear recognition by students that testing of knowledge followed by immediate feedback prompted a much deeper analysis of the subject matter, supporting constructivist principles of learning, which Marello (2014) refers to as the 'learning loop' an essential aspect of gaming design.

There was no evidence to support postulations that failure to get on the 'leader board' would discourage continuation in the game and lead to disruptive behaviour (Plass et al., 2015; Plump \& LaRosa, 2017). This did not appear in any of the qualitative feedback and, as students began to reassess their own interpretations of the questions and answers, this in fact invoked further discussions around the nuances of content, avoiding any preconceived ideas on the part of the lecturer with regard to students' knowledge. Students were certainly supported in their metacognition and reflective thinking by the sense of learning together and not struggling alone, what Plass et al. (2015, p. 261) refer to as 'graceful failure', a clear reminder that the role of the lecture as a social function in transformational learning should not be underestimated (Bates et al., 2017).

While there was some discourse on the ideal length of discussion episodes and lecture duration. The greatest area of contention was around the impact of game-based learning on retention. While the majority of students were able to articulate their participatory learning experience in terms of facilitating deep learning, others did not make the connection with longer term retention, directly contradicting the findings of Masikunis et al. (2009). Grimley et al. (2011) urge caution in assuming that student satisfaction will automatically translate into longer term retention despite strong support from educational literature suggesting otherwise (French \& Kennedy, 2017).

Bates et al. (2017) argues that learners are driven by personal and professional motivations and that 'fun' is not always the deciding factor in students' engagement; the 
potential learning benefits are. This was clearly visible in the outcomes of this study where engagement did not alter the penchant of some students towards note taking. This 'dependency' might also, subconsciously, reflect the desire for a more traditional 'sage on the stage' approach, aligning with more normal student expectations. Sharp et al. (2017) reflect on how lectures often take students out of their 'listening zones' but rarely out of their 'comfort zones' and perhaps, unwittingly, reinforcing passive learning through passive absorption. There is obvious scope here for further research, on a more comprehensive scale, into the emotional aspects of learning and impact on longer term retention.

Clearly, the learning process is both individual and complex but as Grimley et al. (2011) remind us, instilling the motivation to learn is crucially important and without such motivation most learning environments are ineffective. Cavanagh (2011) returns us to the ideas of task authenticity which rated highly in both pre and post lecture feedback. Through the adoption of a game-based approach to blended leaning the lecture theatre environment was transformed, without any changes to the physical elements of the building, and valuable face to face contact was retained. By capitalising on the university's free internet provision, and proliferation of personal mobile devices, a more entertaining, engaging and socially interactive learning space was created. Students became more active participants in their own learning and were able to explore concepts at a greater depth and develop their understanding through a more conscious involvement in the learning process. Students reported positively on improvements in engagement, concentration and to a lesser extent retention.

This study lends weight to other studies claiming that student learning experience in large classes can be enhanced by technology and provides evidence to challenge studies which suggest that a game-based approach to learning when applied in 
an educational setting reduces elements of fun, excitement and motivation (Grimley et al., 2011). Clearly further research, and a more thorough embedding of blended learning consistently throughout the module, would be necessary to confidently suggest that this approach would impact on engagement and eventually outcomes and there is also significant mileage in exploring Wang (2015) work on technological fatigue associated with longer term exposure to game-based learning.

\section{References}

Aljezawi, M. \& Albashtawy, M. (2015). Quiz game teaching format versus didactic lecture. British Journal of Nursing, 24(1), 86-92.

Arvanitakis, J. (2014). Massification and the large lecture theatre: from panic to excitement. Higher Education, 67(6), 735-745.

Bates, M., Curtis, S. \& Dismore, H. (2017). Learning approaches and lecture attendance of medical students. Journal of Further and Higher Education, 1-11.

Biggs, J. \& Tang, C. (2011). Teaching for quality learning at university. Maidenhead: SRHE \& Open University Press.

Bligh, D. (2000). What's the use of lectures? San Francisco: Jossey-Bass Publishers.

Cavanagh, M. (2011). Students' experience of active engagement through cooperative learning activities in lectures. Active Learning in Higher Education, 12(1), 2333.

Cohen, L., Manion, L. \& Morrison, K. (2011). Research methods in education. London: Routledge.

Exeter, D. J., Ameratunga, S., Ratima, M., Morton, S., Dickson, M., Hsu, D. \& Jackson, R. (2010). Student engagement in very large classes: the teachers' perspective. Studies in Higher Education, 35(7), 761-777.

Exley, K. (2010). Encouraging active learning in lectures. All Ireland Journal of Teaching and Learning in Higher Education, 2(1), 10.1-10.8.

French, S. \& Kennedy, G. (2017). Reassessing the value of university lecturers. Teaching in Higher Education, 22(6), 639-654.

Glazer, F. S. (2012). Blended learning: across the disciplines, across the academy. Sterling, Virginia: Stylus Publishing. 
Goffe, W. L. \& Kauper, D. (2014). A survey of principle instructors: Why lecture prevails. The Journal of Economic Education, 45(4), 360-375.

Grimley, M., Green, R., Nilsen, T., Thompson, D. \& Tomes, R. (2011). Using computer games for instruction: The student experience. Active Learning in Higher Education, 12(1), 45-56.

Heaslip, G., Donovan, P. \& Cullen, J. G. (2014). Student response systems and learner engagement in large classes. Active Learning in Higher Education, 15(1), 11-24.

Hornsby, D. J. \& Osman, R. (2014). Massification in higher education: large classes and student learning. Higher Education, 67, 711-719.

Luckin, R. (2010). Re-designing learning contexts: Technology-rich, learner-centred ecologies. London: Routledge.

Marello, J. (2014). Kahoot! is a fun free game-based classroom response system. Retrieved from http://www.emergingedtech.com/2014/07/kahoot-game-basedclassroom-response-system/

Masikunis, G., Panayiotidis, A. \& Burke, L. (2009). Changing the nature of lectures using a personal response system. Innovations in Education and Teaching International, 46(2), 199-212.

McNiff, J. (2016). You and your action research project. Abingdon: Routledge.

Moore, N. \& Gilmartin, M. (2010). Teaching for better learning: A blended learning pilot project with first year geography undergraduates. Journal of Geography in Higher Education, 34(3), 327-344.

Okaz, A. A. (2015). Integrating blended learning in higher education. Procedia - Social and Behavioural Sciences, 186, 600-603.

Petrovic, J. \& Pale, P. (2015). Students' perceptions of live lectures' inherent disadvantages. Teaching in Higher Education, 20(2), 143-157.

Plass, J. L., Homer, B. D. \& Kinzer, C. K. (2015). Foundations of game-based learning. Educational Psychologist, 50(4), 258-283.

Plump, C. M. \& LaRosa, J. (2017). Using Kahoot! in the classroom to create engagement and active learning: A game based technology solution for eLearning novices. Management Teaching Review, 2(2), 151-158.

Saunders, F. C. \& Gale, A. (2012). Digital or didactic: Using technology to confront the challenge of large cohort teaching. British Journal of Educational Technology, 43(6), 847-858. 
Sharp, J. G., Hemmings, B., Kay, R., Murphy, B. \& Elliot, S. (2017). Academic boredom among students in higher education: A mixed methods exploration of characteristics, contributors and consequences. Journal of Further and Higher Education, 41(5), 657-677.

Schmidt, H. G., Wagener, S. L., Smeets, G., Keemink, L. M. \& Van der Molen, H. T. (2015). On the use and misuse of lectures in higher education. Health Professions Education, 1, 12-18.

Snart, J. A. (2010). Hybrid learning: The perils and promises of blended online and face to face instruction in higher education. Oxford: Praeger.

Tormey, R. \& Henchy, D. (2008). Re-imagining the traditional lecture: an action research approach to teaching student teachers to 'do' philosophy. Teaching in Higher Education, 13(3), 303-314.

Wang, A. I. (2015). The wear out effect of a game-based student response system. Computers \& Education, 82(C), 217-27.

Wang, A. I. \& Lieberoth, A. (2016, October). The effects of points and audio on concentration, engagement, enjoyment, learning, motivation, and classroom dynamics using Kahoot! Proceedings from the 10th European Conference of Game Based Learning.

Wells, V. K. \& Daunt, K.L. (2016). Eduscape: The effects of servicescapes and emotions in academic learning environments. Journal of Further and Higher Education, 40(4), 486-508.

Wolff, M., Wagner, M. J., Poznanski, S., Schiller, J. \& Santen, S. (2015). Not another boring lecture: Engaging learners with active learning techniques. The Journal of Emergency Medicine, 48(1), 85-93.

Zarzycka-Piskorz, E. (2016). Kahoot it or not? Can games be motivating in learning grammar? Teaching English with Technology, 16(3), 17-36. 
Table 1. Pre-event survey profiles, mean scores and standard deviations

\begin{tabular}{|c|c|c|c|c|c|c|c|}
\hline & \multicolumn{5}{|c|}{ Response profile frequency and percentages } & \multirow[b]{2}{*}{ Mean } & \multirow[b]{2}{*}{$\begin{array}{l}\text { Standard } \\
\text { Deviation }\end{array}$} \\
\hline & $\begin{array}{l}\text { Never } \\
(1)\end{array}$ & $\begin{array}{c}\text { Not } \\
\text { very } \\
\text { often } \\
(2)\end{array}$ & $\begin{array}{l}\text { About } \\
\text { half (3) }\end{array}$ & $\begin{array}{c}\text { Most } \\
\text { of the } \\
\text { time } \\
(4)\end{array}$ & $\begin{array}{l}\text { All of } \\
\text { the } \\
\text { time } \\
(5)\end{array}$ & & \\
\hline Engagement & 0 & $\begin{array}{c}3 \\
(6.8)\end{array}$ & $\begin{array}{c}26 \\
(59.1)\end{array}$ & $\begin{array}{c}15 \\
(34.1)\end{array}$ & 0 & 3.27 & 0.58 \\
\hline Retention & 0 & $\begin{array}{c}5 \\
(11.4)\end{array}$ & $\begin{array}{c}23 \\
(52.3)\end{array}$ & $\begin{array}{c}16 \\
(36.4)\end{array}$ & 0 & 3.25 & 0.64 \\
\hline Concentration & 0 & $\begin{array}{c}4 \\
(9.1) \\
\end{array}$ & $\begin{array}{c}26 \\
(59.1)\end{array}$ & $\begin{array}{c}14 \\
(31.8)\end{array}$ & 0 & 3.23 & 0.60 \\
\hline
\end{tabular}


Table 2. Post event survey profiles, mean scores and standard deviations

\begin{tabular}{|c|c|c|c|c|c|c|c|}
\hline & \multicolumn{5}{|c|}{ Response profile frequency and percentages } & \multirow[b]{2}{*}{ Mean } & \multirow[b]{2}{*}{$\begin{array}{l}\text { Standard } \\
\text { Deviation }\end{array}$} \\
\hline & $\begin{array}{l}\text { Not at } \\
\text { all } \\
\text { useful } \\
\text { (1) }\end{array}$ & $\begin{array}{c}\text { Not } \\
\text { very } \\
\text { useful } \\
(2)\end{array}$ & $\begin{array}{c}\text { Fairly } \\
\text { useful } \\
\text { (3) }\end{array}$ & $\begin{array}{c}\text { Useful } \\
\text { (4) }\end{array}$ & $\begin{array}{l}\text { Very } \\
\text { useful } \\
(5)\end{array}$ & & \\
\hline Engagement & 0 & $\begin{array}{c}1 \\
(2.3)\end{array}$ & $\begin{array}{c}8 \\
(18.2)\end{array}$ & $\begin{array}{c}18 \\
(40.9)\end{array}$ & $\begin{array}{c}17 \\
(38.6)\end{array}$ & 4.16 & 0.80 \\
\hline Retention & 0 & $\begin{array}{c}7 \\
(15.9)\end{array}$ & $\begin{array}{c}13 \\
(29.6)\end{array}$ & $\begin{array}{c}19 \\
(43.2)\end{array}$ & $\begin{array}{c}5 \\
(11.4)\end{array}$ & 3.50 & 0.89 \\
\hline Concentration & 0 & 0 & $\begin{array}{c}11 \\
(25.0)\end{array}$ & $\begin{array}{c}19 \\
(43.2)\end{array}$ & $\begin{array}{c}14 \\
(31.8)\end{array}$ & 4.07 & 0.76 \\
\hline Discussion & 0 & $\begin{array}{c}1 \\
(2.3)\end{array}$ & $\begin{array}{c}10 \\
(22.7)\end{array}$ & $\begin{array}{c}23 \\
(52.3)\end{array}$ & $\begin{array}{c}10 \\
(22.7)\end{array}$ & 3.96 & 0.74 \\
\hline Interactive & 0 & 0 & $\begin{array}{c}4 \\
(9.1) \\
\end{array}$ & $\begin{array}{c}12 \\
(27.3)\end{array}$ & $\begin{array}{c}28 \\
(63.6) \\
\end{array}$ & 4.6 & 0.77 \\
\hline
\end{tabular}

